\title{
Spontanous periodic breathing is associated with sympathetic hyperreactivity and baroreceptor dysfunction in hypertension
}

\author{
Binggeli, C ; Sudano, I ; Corti, R ; Spieker, L ; Jenni, R ; Lüscher, T F ; Noll, G
}

\begin{abstract}
OBJECTIVES: Intermittent periods of hypoxemia such as during periodic breathing are associated with hypertension and increased sympathetic activity. In patients with sleep apnea syndrome, hypertension is common. Treating apnea improves hypertension and reduces sympathetic outflow. The aim of the present study was to investigate the phenomenon and mechanisms of spontaneous periodic breathing in patients with hypertension. METHOD: We examined 43 hypertensive patients with untreated hypertension without left-ventricular dysfunction, heart failure or sleep apnea syndrome. Muscle sympathetic nerve activity (MSA), heart rate (HR), blood pressure (BP) and respiration were continuously recorded at rest and during cold-pressor testing. Oxygen and a CO2-enriched gas were used to test central and peripheral chemoreceptors, respectively. Baroreceptor gain was measured using the alpha method. RESULTS: Seven out of 43 patients showed spontaneous periodic breathing while awake. No difference in MSA, HR and BP was seen between patients with and without periodic breathing at rest except the breathing pattern. However, the cold-pressor test caused a larger increase of MSA in patients with periodic breathing $(203+/-62$ vs. $62+/-8 \%, \mathrm{P}<0.0001$ by ANOVA), as well as systolic (46 +/6 vs. $25+/-3 \mathrm{mmHg}, \mathrm{P}=0.002)$ and diastolic $\mathrm{BP}(26+/-5$ vs. $12+/-1 \mathrm{mmHg}, \mathrm{P}=0.004$, ANOVA). Baroreceptor gain was markedly higher in patients with periodic breathing. Chemoreceptor sensitivity was comparable. CONCLUSION: Spontaneous periodic breathing is relatively common in patients with hypertension and is associated with greatly enhanced responses to cold-pressor testing. We suggest increased baroreceptor gain and sympathetic outflow as a cause for the oscillatory respiration pattern via barorespiratory coupling.
\end{abstract}

DOI: https://doi.org/10.1097/HJH.0b013e3283370e3d

Posted at the Zurich Open Repository and Archive, University of Zurich

ZORA URL: https://doi.org/10.5167/uzh-36366

Journal Article

Accepted Version

Originally published at:

Binggeli, C; Sudano, I; Corti, R; Spieker, L; Jenni, R; Lüscher, T F; Noll, G (2010). Spontanous periodic breathing is associated with sympathetic hyperreactivity and baroreceptor dysfunction in hypertension. Journal of Hypertension, 28(5):985-992.

DOI: https://doi.org/10.1097/HJH.0b013e3283370e3d 
Journal of Hypertension

17. 12. 2009

\title{
Spontanous Periodic Breathing is Associated with Sympathetic Hyperreactivity and Baroreceptor Dysfunction in Hypertension
}

Running Title Sympathetic Overactivity and Periodic Breathing

\author{
Christian Binggeli ${ }^{a *}$, Isabella Sudano ${ }^{a *}$, Roberto Corti ${ }^{a, b}$, Lukas Spieker ${ }^{a}$, \\ Rolf Jenni ${ }^{\mathrm{a}, \mathrm{b}}$, Thomas F. Lüscher ${ }^{\mathrm{a}, \mathrm{b}}$ and Georg Noll ${ }^{\mathrm{a}, \mathrm{b}}$ \\ * both author contributed equally to this paper \\ ${ }^{a}$ Cardiovascular Center Cardiology, University Hospital Zürich, Switzerland \\ ${ }^{b}$ Center for Integrative Human Physiology, University of Zurich, Switzerland
}

Acknowledgment of grants and other support: This study was supported by the Swiss National Research Foundation (32-52690-97).

Conflict of Interest: none of declared.

\section{Corresponding author:}

Georg Noll, MD

Cardiovascular Center Cardiology

University Hospital

Rämistrasse 100

$\mathrm{CH}-8091$ Zürich, Switzerland

E-mail: karnog@usz.unizh.ch

Phone: ++41442552182

Fax: $\quad++41442554597$

Word count: 4654 - text including title page, abstract (250), condensed abstract (69) and references. 


\begin{abstract}
Objectives Intermittent periods of hypoxemia such as during periodic breathing are associated with hypertension and increased sympathetic activity. In patients with sleep apnea syndrome, hypertension is common. Treating apnea improves hypertension and reduces sympathetic outflow. The aim of the present study was to investigate the phenomenon and mechanisms of spontaneous periodic breathing in patients with hypertension.
\end{abstract}

Method We examined 43 hypertensive patients with untreated hypertension without left ventricular dysfunction, heart failure or sleep apnea syndrome. Muscle sympathetic nerve activity (MSA), heart rate $(H R)$, blood pressure $(B P)$ and respiration were continuously recorded at rest and during cold pressor testing. Oxygen and a $\mathrm{CO}_{2}{ }^{-}$ enriched gas were used to test central and peripheral chemoreceptors, respectively. Baroreceptor gain was measured using the alpha method.

Results 7 out of 43 patients showed spontaneous periodic breathing while awake. No difference in MSA, HR and BP was seen between patients with and without periodic breathing at rest except the breathing pattern. However, the cold pressor test caused a larger increase of MSA in patients with periodic breathing (203 \pm 62 vs. $62 \pm 8 \%, p<0.0001$ by ANOVA), as well as systolic ( $46 \pm 6$ vs. $25 \pm 3 \mathrm{mmHg}, \mathrm{p}=0.002)$ and diastolic BP $(26 \pm 5$ vs. $12 \pm 1$ $\mathrm{mmHg}, \mathrm{p}=0.004$, ANOVA). Baroreceptor gain was markedly higher in patients with periodic breathing. Chemoreceptor sensitivity was comparable.

Conclusion Spontaneous periodic breathing is relatively common in patients with hypertension and is associated with greatly enhanced responses to cold pressor testing. We suggest increased baroreceptor gain and sympathetic outflow as a cause for the oscillatory respiration pattern via baro-respiratory coupling. 


\section{Condensed Abstract}

Periodic breathing, which is associated with various cardiovascular diseases was found in a considerable number of hypertensive patients. Sympathetic and blood pressure reactivity in response to the cold pressor test was greatly enhanced and baroreceptor sensitivity was markedly higher in patients with periodic breathing while chemoreceptor sensitivity was comparable between the groups. Increased baroreceptor gain and sympathetic outflow is suggested to cause the oscillatory respiration pattern via barorespiratory coupling.

Keywords: blood pressure-physiology; sympathetic nervous system; chemoreceptorsphysiology; baroreceptor-physiology. 


\section{INTRODUCTION}

The sympathetic nervous system (SNS) plays an important role in cardiovascular regulation. Its activity has important pathogenetic and prognostic impact in a wide spectrum of cardiovascular disorders. Thus, factors influencing the activity of the sympathetic nervous system are of major interest.

Periodic breathing (PB) of central origin such as it occurs in heart failure has been described 150 years ago by Cheyne and Stokes and is an independent marker of an increased mortality.[1] It goes along with sympathetic activation; however the pattern of activation differs from obstructive apnea.[2] The resulting blood pressure elevation is blocked by the ganglionic blocker trimethaphan and thus neuronally mediated. Lowpressure receptors do not substantially contribute to sympathetic activation since endexpiratory breath holds and the sustained Mueller maneuver increase sympathetic activity to a similar extent despite different intra-thoracic pressure.[3]

Recent animal experiments indicate that chronic intermittent hypoxia leads to hypertension. In a rat model, repetitive periods of hypoxia over 30 days caused hypertension persisting beyond the exposure to intermittent hypoxia.[4] In dogs, hypoxic episodes due to repetitive airway obstruction during sleep resulted in acute transient increases in nighttime blood pressure and eventually provoked a sustained daytime hypertension.[5]

It is likely that the same mechanisms are valid in humans too, since obstructive sleep apnea leads to increased SNS activity and increased daytime blood pressure.[6-8] Obstructive breathing disorders are associated with cardiovascular diseases such as hypertension,[9-11] myocardial infarction,[12] stroke,[13] and heart failure.[14] When 
treated with continuous positive airway pressure (CPAP) during sleep, daytime blood pressure and sympathetic activity decrease.[15, 16] Similarly, in medically treated patients with heart failure, treatment of coexisting obstructive sleep apnea by CPAP reduces systolic blood pressure, sympathetic activity, improves left ventricular function[17] and increases oxygen body stores[18], while mild hyperoxia did not reduce sympathetic drive indicating that peripheral chemoreceptors do not contribute to sympathetic activation.[19] Slowing respiratory rate with respiratory training in patients with heart failure decreased dyspnea and increased exercise performance.[20] Thus, there is evidence that intermittent periods of hypoxia - central or obstructive - lead to elevated blood pressure both in the short and long term.

In the run-in placebo phase of a clinical trial we noticed an unexpected high prevalence of a periodic breathing pattern in awake hypertensive patients without heart failure or sleep disorder. The aim of the present study was to investigate the phenomenon and mechanisms of spontaneous PB in conscious patients with hypertension and to delineate its impact on sympathetic regulation. 


\section{METHODS}

\section{Subjects}

We examined 43 patients ( 31 men, 12 women) with arterial hypertension (diastolic blood pressure 95 to $114 \mathrm{mmHg}$ ) at the end of a 3 weeks placebo washout phase of a randomized double blind trial.[21] Patients treated with vasoactive drugs, with heart failure, pulmonary or hepatic disease were excluded from the study. The study was approved by the local ethics committee and all subjects gave written informed consent prior to study begin.

\section{Measurements and Interventions}

Patients were studied fasting between 9 and 11 AM in a quiet, temperature-controlled room in the supine position at rest and during cold pressor test (CPT) as previously described.[22, 23] Muscle sympathetic activity (MSA), ECG, non-invasive blood pressure (Finapres, Ohmeda, Englewood, CO) and respiration (strain gauge) were continuously recorded using a LabView application, a MIO 16L (National Instruments, TX, U.S.A.) A/D conversion board and a Macintosh Computer (Apple Inc. Cupertino, CA, U.S.A.). The signals were sampled at $500 \mathrm{~Hz}$ and stored with 12-bit accuracy. Blood pressure was measured every 5 minutes during rest and every minute during CPT using a sphygmomanometer (Dynamap, Critikon, Tampa, FL, U.S.A.). Percent change of minute ventilation was estimated based on the strain gauge recording. 


\section{Sympathetic nerve activity}

Sympathetic nerve activity was recorded continuously using microneurography as previously described. In brief, electrical activity of muscle vasoconstrictor fibers was measured in the peroneal nerve, posterior to the fibular head by use of tungsten microelectrodes (shaft diameter $200 \mu \mathrm{m}$, tapering to an uninsulated tip of 1-5 $\mu \mathrm{m}$ ).[24, 25] A subcutaneous reference electrode was inserted 1 to $2 \mathrm{~cm}$ away from the recording electrode. The neural signal was amplified, filtered, rectified and integrated to obtain a mean voltage neurogram of sympathetic activity.

Measurements were taken at rest and during CPT. For the CPT, patients were asked to immerge one hand into ice water $\left(0^{\circ} \mathrm{C}\right)$ up to the wrist for 2 minutes. We choose to use CPT as this test is a well-known stimulus for the sympathetic nervous system.[26] Moreover, during CPT there is a positive correlation between the increases in MSA and the increases in arterial pressure and this test may unmask an increased sympathetic nervous activity, which is one of the underlying mechanisms of hypertension. [26]

\section{Peripheral chemoreceptor testing.}

Patients with PB were given oxygen by mask (Intersurgical, England) to test peripheral chemoreceptors. After habituation to the mask, patients breathed room-air during 5 minutes to obtain a baseline value. Then oxygen was administered at $6 \mathrm{I} / \mathrm{min}$ for 5 minutes to deactivate peripheral chemoreceptors and test their contribution to the sympathetic drive. Oxygen was followed by room air for 5 minutes. Five hypertensive patients without PB underwent the same procedure as control. 


\section{Central chemoreceptor testing.}

Patients with PB and 6 hypertensive control subjects with normal breathing pattern were tested using $7 \% \mathrm{CO}_{2}$ and $93 \%$ oxygen during 3 minutes over a mouthpiece to centrally stimulate respiration. Before the measurement, the subjects breathed room air over the mouthpiece to get used to the procedure.

Baroreceptor function. Baroreceptor function was estimated using the alpha method.[27] [28] The alpha coefficient was calculated as the squared root of the ratio of $\mathrm{R}-\mathrm{R}$ interval and SBP powers[28] in the frequency domain. This relies on the assumption that the ratio between $R-R$ interval and SBP powers in the frequency regions where they are coherent is a reflection of baroreflex function.

This method was validated by animal experiment and the [alpha] coefficient demonstrated a relatively close correlation between [alpha] coefficient values and the estimates of baroreflex-sensitivity obtained by i.v. bolus injection of phenylephrine or nitroglycerine.[28]

\section{Paced breathing.}

Paced breathing use increases reliability of heart rate variability analysis.[29]

Therefore, in our study all patients with PB and 6 hypertensive control subjects were studied during spontaneous breathing and paced breathing (breathing at 15 /min during 3 minutes). 


\section{Echocardiography.}

To exclude systolic left ventricular-dysfunction, which is associated with PB, transthoracic echocardiography was performed in patients with PB. Systolic leftventricular function was derived from biplane apical views. Left-ventricular dimensions and mass were measured using parasternal M-mode imaging.[30] Diastolic leftventricular function was assessed using mitral valve inflow and pulmonary vein flow pattern.

\section{Exclusion of sleep apnea.}

The presence of sleep apnea was excluded by history using a standard screening questionnaire[31].

\section{Analyses}

PB was diagnosed by inspection of the original strain gauge tracing, by clinical observation and spectral analysis of the respiratory signal revealing a distinct low frequency peak. Periods of 3 minutes were taken to calculate the spectral power of the respiratory oscillations. A peak in the very-low-frequency range between 0.005 and 0.05 $\mathrm{Hz}$, containing more than one third of the total power of the respiratory signal was taken as objective criterion to confirm PB.

The respiratory, blood pressure and MSA recordings of the healthy volunteers were analyzed by an investigator blinded to the history of the subject.[32] MSA-signal was evaluated with a program written in MatLab (The Mathworks Inc., Natick, MA).[21] The program detects the time of a burst, its amplitude and the area under the curve. Parameters are given as mean values of one minute. 


\section{Statistical analysis}

Data were analyzed with repeated-measures ANOVA (Bonferroni correction) for the CPT and paired Student's t-tests for comparison of oxygen and room-air breathing. MSA during the CPT is given as per cent change compared to 3 minutes of baseline before CPT. The effects of oxygen breathing and $\mathrm{CO}_{2}$ breathing are given as change from baseline. Results are expressed as means \pm SEM. $\mathrm{P}<0.05$ was considered statistically significant. 


\section{RESULTS}

\section{Clinical characteristics}

Baseline characteristics such as heart rate, systolic and diastolic blood pressure and body mass index were comparable in patients with and without PB (Table 1).

In 7 out of 43 hypertensive patients (16\%) PB at rest was confirmed by a distinct very low frequency peak in the breathing spectrum, corresponding to a cycle length of approximately 35 seconds. In hypertensive patients with spontaneous PB, these verylow-frequency oscillations did translate into corresponding very-low-frequency oscillations of heart rate and blood pressure (Figure 1). Echocardiography was performed in 6 of the 7 patients with PB. All of them had normal systolic function without regional wall motion abnormalities. Mean left ventricular muscle mass index was $121 \pm 9$ $\mathrm{g} / \mathrm{m}^{2}$. Diastolic dysfunction (mitral inflow, pulmonary vein flow) was present in 5 out of 6 patients.

\section{Cold pressor test}

Among the hypertensive study population, resting MSA did not differ between patients with $\mathrm{PB}$ and without $\mathrm{PB}(45.7 \pm 5$ vs. $49.2 \pm 1.6$ bursts/min, $73 \pm 6$ vs. $75 \pm 2$ bursts $/ 100$ heart beats respectively, ns.). During CPT patients with PB showed a larger increase of MSA ( $+203 \pm 62$ vs. $+62 \pm 8 \%, p<0.0001$, Figure 2 A), systolic ( $+46 \pm 6$ vs. $+25 \pm 3 \mathrm{mmHg}, p=0.002$ ) and diastolic blood pressure $(+26 \pm 5$ vs. $+12 \pm 1 \mathrm{mmHg}, \mathrm{p}=0.004)$ compared to patients without PB (Figure 2 B). Heart rate similarly increased in patients with $P B\left(+5.5 \pm 1.9 \mathrm{~min}^{-1}, p=0.02\right.$ vs. baseline) and patients without PB (+6.6 $\pm 0.9, p<0.0001$ vs. baseline $)$. 


\section{Peripheral chemoreceptor deactivation with $\mathrm{O}_{2}$ breathing}

Five minutes of oxygen breathing increased $\mathrm{O}_{2}$-saturation from $94.8+0.5 \%$ to $98.3 \pm 0.4 \%(p<0.0001)$ and significantly decreased HR $\left(-1.2 \pm 0.7 \mathrm{~min}^{-1}, p=0.004\right.$ vs. baseline) in patients with PB and in patients without PB $\left(-0.9 \pm 1.0 \mathrm{~min}^{-1}, \mathrm{p}=0.03\right.$ vs. baseline) (Table 2). Oxygen-breathing for 5 minutes slightly decreased diastolic blood pressure in patients without PB but had no effect on MSA.

\section{Central respiratory stimulation by $\mathrm{CO}_{2}$ breathing}

Central respiratory stimulation by breathing of $\mathrm{CO}_{2}$-enriched gas equally increased minute ventilation in patients with PB (96 $\pm 37 \%, p<0.05$ vs. baseline) and in patients without PB (96 $\pm 32 \%, p<0.05$ vs. baseline) as well as MSA $(4.2 \pm 1.3 \mathrm{~b} / \mathrm{min}, \mathrm{p}=0.03$ and $87 \pm 40 \%$ of total activity, $\mathrm{p}=0.007)$ and $(2.4 \pm 0.7 \mathrm{~b} / \mathrm{min}, \mathrm{p}=0.02$ and $55 \pm 50 \%$ of total activity, $p=0.03$ ) respectively (Table 2). Systolic blood pressure increased in patients with $\mathrm{PB}$ by $4.4 \pm 1.5 \mathrm{mmHg}, \mathrm{p}=0.03$ and in patients without $\mathrm{PB}(6.5 \pm 1.7 \mathrm{mmHg}, \mathrm{p}=0.009)$ without any difference between groups. Diastolic blood pressure remained unchanged in patients with $\mathrm{PB}(1.3 \pm 0.6 \mathrm{mmHg}$, ns.) and increased $(3.1 \pm 1.2 \mathrm{mmHg}, \mathrm{p}=0.04)$ in patients without PB. Heart rate increased by $1.9 \pm 0.7 \mathrm{bpm}$ in the group with periodic breathing ( $p=0.05$ vs. baseline) and $1.4 \pm 0.7 \mathrm{bpm}$ in the group without PB ( $p=n s$.).

\section{Paced breathing}

Paced breathing (Table 2) resulted in a small decrease of MSA in patients with PB ($1.8 \pm 0.6 \mathrm{~b} / \mathrm{min}, \mathrm{p}=0.04 \mathrm{vs}$. baseline) but not in patients with normal breathing. There was no significant change in systolic blood pressure. Diastolic blood pressure was unaffected in patients with PB and decreased by $3.2 \pm 0.8 \mathrm{mmHg}$ in patients without PB 
( $p=0.009$ vs. baseline). $\mathrm{O}_{2}$ saturation increased by $1.8 \pm 0.5 \%(p=0.003$ vs. baseline $)$ during paced breathing without intergroup difference. Paced breathing equally increased minute ventilation in patients with PB and without PB, respectively $(107 \pm 35 \%$ vs. $85 \pm 27 \%, p=n s$.$) .$

\section{Baroreceptor function}

Baroreceptor sensitivity in the high frequency range was comparable in patients with PB $(10.2 \pm 2.5 \mathrm{~ms} / \mathrm{mmHg})$ and patients without PB $(10.5 \pm 1.2 \mathrm{~ms} / \mathrm{mmHg})$, whereas in the low frequency range the sensitivity was significantly higher in patients with PB $(10.4 \pm 1.0$ $\mathrm{ms} / \mathrm{mmHg}$ ) compared to patients without periodic breathing $(5.2 \pm 0.5 \mathrm{~ms} / \mathrm{mmHg}$, $p<0.0001$, Figure 3). 


\section{DISCUSSION}

This study shows that spontaneous PB is relatively common in awake hypertensive patients without sleep apnea, left ventricular dysfunction or heart failure. Spontaneous PB was associated with a markedly enhanced reactivity of blood pressure and sympathetic activity to a physiologic stimulus. The sympathetic response to the cold pressor test was markedly more pronounced compared to controls. An increased sympathetic nervous activity has a negative prognostic impact in patients with cardiovascular disease such as heart failure,[33] myocardial infarction,[34] and stroke.[35]

Baroreceptor gain for slow changes of blood pressure was considerably higher in patients with PB representing increased controller gain in the baroreceptor feedback loop.

Feedback systems are important elements of cardiorespiratory regulation. They consist of a controller (chemoreceptors, baroreceptors), a plant whose effect or output is regulated by the controller and a communication channel through which the controller is informed about the effect of the plant. Chemoreflexes are powerful modulators of breathing as well as of neural circulatory control. They are subject to important negative feedback interactions as chemoreceptors give important inputs for the regulation of the sympathetic nerve activity, while thoracic afferents inhibit sympathetic outflow.

Our experiments support the hypothesis that cyclic inhibition of respiration by carotid and aortic baroreceptors contributes to oscillations in the breathing pattern of hypertensive patients. Indeed, the link between aortic and carotid baroreceptors and the control of the respiratory center has already been demonstrated by Heymans who was 
awarded the Nobel prize in 1938. He showed that arterial hypertension in the cardioaortic vascular area and in the carotid artery inhibits the activity of the respiratory center by a reflex mechanism, while hypotension has stimulatory effects upon breathing.[36] Indeed, marked blood pressure surges were followed by cyclic depression of respiration or apnea in our patients. A study in patients with pacemakers and sleep apnea syndrome showed that the stabilization of heart rate and in turn blunting baroreceptormediated oscillations of cardiac output by atrial overdrive pacing reduces the severity of the breathing disorder.[37]

Conversely, central and peripheral chemoreceptors do not seem to be involved in the underlying sympathetic dysregulation, as $\mathrm{CO}_{2}$-breathing and hyperoxic deactivation of peripheral chemoreceptors led to similar respiration responses in our patients with and without PB. Baroreceptor gain in the low frequency range however, was twice as pronounced in patients with PB compared to the control group, indicating that arterial baroreceptors are much more sensitive to slow changes of blood pressure in patients with PB.

Chemoreflex physiology is complex and the exact mechanisms by which both peripheral and central chemoreceptors are activated remains unclear. Periodic breathing of central origin is thought to origin from instability of the feedback circuit. Although such loops act to minimize effects of disturbances on the output, they can become oscillatory. In heart failure patients, periodic breathing is common and an increased sensitivity to $\mathrm{CO}_{2}$ has been found.[38] We hypothesized initially that an increased controller gain of chemoreceptors would be involved in respiratory oscillations, however, in patients with or without $\mathrm{PB}, \mathrm{CO}_{2}$ sensitivity was comparable. Moreover, hyperoxic deactivation of peripheral chemoreceptors did not influence MSA in either of the groups but slightly lowered heart rate in both groups. The former finding is in line with the effect of oxygen 
breathing in heart failure patients.[39] Thus, altered controller gain of central as well as peripheral chemoreceptors is not involved in PB in hypertensive patients.

There is widespread evidence that hypoxia acutely increases sympathetic activity and consecutively peripheral resistance and blood pressure. The hypertensive effect of chronic intermittent hypoxia outlasts hypoxemia in animal models.[4, 5] Morgan et al. demonstrated in healthy volunteers that hypoxic hypercapnia leads to a protracted increase in MSA, whereas hyperoxic hypercapnia only transiently increases sympathetic activity indicating that hypoxemia is responsible for the effect.[40] Chronic intermittent hypoxia has thus clinically relevant prolonged effects on blood pressure in animal models.

We used a strain gauge for the assessment of breathing. The strain gauge has several disadvantages compared to the pneumotachograph. Particularly, it does not allow exact quantification of respiratory volumes. However, the use of a mouthpiece as it is required with the pneumotachograph as well as the awareness of recording substantially influences the breathing pattern.[41] We aimed to identify irregularities in the breathing pattern with minimal awareness of the subjects of the recording rather than to exactly quantify respiratory flow. For this purpose, the strain gauge method used in this study might be more appropriate.

Some limitations of our study have to be emphasized: as first the assessment of the baroreceptor function was based only on the low frequency/high frequency analysis, however, the use of paced breathing improved the reliability of spectral parameters such as LF/HF. 
Moreover, even if CPT is a wide used test to increase sympathetic nervous activity this test presents indeed a large intraindividual variability (reliability) and a limited reproducibility.[42, 43]

In summary our study provides evidence for the presence of PB in a considerable number of hypertensive patients. PB was associated with greatly enhanced responses to cold pressor testing, indicating a potentiation of sympathetic outflow. We suggest increased baroreceptor gain and sympathetic outflow as a cause for the oscillatory respiration pattern via baro-respiratory reflex mechanism. Increased gain of central and peripheral chemoreflexes does not seem to be an important cause. Further studies will define the incidence of PB as potential cause of arterial hypertension. In addition, interventional studies should be planned to clarify the potential therapeutic implications. 


\section{Acknowledgements}

This research was supported by the Swiss national research foundation to G.N. (3252690-97). The authors gratefully acknowledge the assistance of Rosy Hug.

\section{Conflict of interest statement}

The study was investigator initiated and investigator driven. The authors report no actual or potential conflicts of interest in connection with this study. 


\section{Figure Legends}

\section{Figure 1:}

Original recording of respiration, heart rate, blood pressure, and muscle sympathetic nerve activity in a hypertensive patient with normal breathing or periodic breathing and spectral analysis of the same parameters. Note the oscillatory pattern of respiration, heart rate, blood pressure and muscle sympathetic nerve activity in periodic breathing. Abbreviations: HR: heart rate $(1 / \mathrm{min}), \mathrm{BP}$ : blood pressure $(\mathrm{mmHg}), \mathrm{MSA}$ : muscle sympathetic nerve activity (V).

\section{Figure 2:}

A) Muscle sympathetic activity (MSA) during the cold pressor test (CPT) increases more markedly in patients with periodic breathing.

B) Systolic and diastolic blood pressure (BP) changes during CPT. The blood pressure increase during CPT is more pronounced in patients with periodic breathing.

\section{Figure 3:}

Baroreceptor sensitivity in patients with (white bars) and without (black bars) periodic breathing in the high frequency (HF) and in the low frequency range (LF) calculated with the alpha method. Low frequency gain is markedly higher in patients with periodic breathing $(\mathrm{p}<0.0001)$. 


\section{References}

1. Ponikowski P, Anker SD, Chua TP, Szelemej R, Piepoli M, Adamopoulos S, et al. Depressed heart rate variability as an independent predictor of death in chronic congestive heart failure secondary to ischemic or idiopathic dilated cardiomyopathy. Am J Cardiol 1997; 79:1645-50.

2. Shimizu T, Takahashi Y, Kogawa S, Takahashi K, Saito Y, Hishikawa Y, et al. Muscle sympathetic nerve activity during central, mixed and obstructive apnea: are there any differences? Psychiatry Clin Neurosci 1997; 51:397-403.

3. Katragadda S, Xie A, Puleo D, Skatrud JB, Morgan BJ. Neural mechanism of the pressor response to obstructive and nonobstructive apnea. J Appl Physiol 1997; 83:2048-54.

4. Lesske J, Fletcher EC, Bao G, Unger T. Hypertension caused by chronic intermittent hypoxia--influence of chemoreceptors and sympathetic nervous system. $J$ Hypertens 1997; 15:1593-603.

5. Brooks D, Horner RL, Kozar LF, Render Teixeira CL, Phillipson EA. Obstructive sleep apnea as a cause of systemic hypertension. Evidence from a canine model [see comments]. J Clin Invest 1997; 99:106-9.

6. Narkiewicz K, van de Borne PJ, Cooley RL, Dyken ME, Somers VK. Sympathetic activity in obese subjects with and without obstructive sleep apnea. Circulation 1998; 98:772-6.

7. Carlson JT, Hedner J, Elam M, Ejnell H, Sellgren J, Wallin BG. Augmented resting sympathetic activity in awake patients with obstructive sleep apnea. Chest 1993; 103:1763-8.

8. Leuenberger U, Jacob E, Sweer L, Waravdekar N, Zwillich C, Sinoway L. Surges of muscle sympathetic nerve activity during obstructive apnea are linked to hypoxemia. $J$ Appl Physiol 1995; 79:581-8.

9. Kales A, Bixler EO, Cadieux RJ, Schneck DW, Shaw LCd, Locke TW, et al. Sleep apnoea in a hypertensive population. Lancet 1984; 2:1005-8.

10. Young T, Peppard P, Palta M, Hla KM, Finn L, Morgan B, et al. Population-based study of sleep-disordered breathing as a risk factor for hypertension. Arch Intern Med 1997; 157:1746-52.

11. Peppard PE, Young T, Palta M, Skatrud J. Prospective study of the association between sleep-disordered breathing and hypertension. N Engl J Med 2000; 342:137884.

12. Hung J, Whitford EG, Parsons RW, Hillman DR. Association of sleep apnoea with myocardial infarction in men [see comments]. Lancet 1990; 336:261-4.

13. Dyken ME, Somers VK, Yamada T, Ren ZY, Zimmerman MB. Investigating the relationship between stroke and obstructive sleep apnea. Stroke 1996; 27:401-7.

14. Malone S, Liu PP, Holloway R, Rutherford R, Xie A, Bradley TD. Obstructive sleep apnoea in patients with dilated cardiomyopathy: effects of continuous positive airway pressure. Lancet 1991; 338:1480-4.

15. Somers VK, Dyken ME, Clary MP, Abboud FM. Sympathetic neural mechanisms in obstructive sleep apnea. J Clin Invest 1995; 96:1897-904. 
16. Becker HF, Jerrentrup A, Ploch T, Grote L, Penzel T, Sullivan CE, et al. Effect of nasal continuous positive airway pressure treatment on blood pressure in patients with obstructive sleep apnea. Circulation 2003; 107:68-73.

17. Kaneko Y, Floras JS, Usui K, Plante J, Tkacova R, Kubo T, et al. Cardiovascular effects of continuous positive airway pressure in patients with heart failure and obstructive sleep apnea. N Engl J Med 2003; 348:1233-41.

18. Krachman SL, Crocetti J, Berger TJ, Chatila W, Eisen HJ, D'Alonzo GE. Effects of nasal continuous positive airway pressure on oxygen body stores in patients with Cheyne-Stokes respiration and congestive heart failure. Chest 2003; 123:59-66.

19. Andreas S, Binggeli C, Mohacsi P, Luscher TF, Noll G. Nasal oxygen and muscle sympathetic nerve activity in heart failure. Chest 2003; 123:366-71.

20. Bernardi L, Spadacini G, Bellwon J, Hajric R, Roskamm H, Frey AW. Effect of breathing rate on oxygen saturation and exercise performance in chronic heart failure. Lancet 1998; 351:1308-11.

21. Binggeli C, Corti R, Sudano I, Luscher TF, Noll G. Effects of chronic calcium channel blockade on sympathetic nerve activity in hypertension. Hypertension 2002; 39:892-6.

22. Binggeli C, Duru F, Corti R, Sudano I, Spieker LE, Turina A, et al. Autonomic nervous system-controlled cardiac pacing: a comparison between intracardiac impedance signal and muscle sympathetic nerve activity. Pacing Clin Electrophysiol 2000; 23:1632-7.

23. Corti R, Binggeli C, Sudano I, Spieker LE, Wenzel RR, Luscher TF, et al. The Beauty and the Beast: Aspects of the Autonomic Nervous System. News Physiol Sci 2000; 15:125-9.

24. Hagbarth KE, Vallbo AB. Pulse and respiratory grouping of sympathetic impulses in human. Acta Physiol Scand 1968; 74:96-108.

25. Delius W, Hagbarth KE, Hongell A, Wallin BG. General characteristics of sympathetic activity in human muscle nerves. Acta Physiol Scand 1972; 84:65-81.

26. Victor RG, Leimbach WJ, Seals DR, Wallin BG, Mark AL. Effects of the cold pressor test on muscle sympathetic nerve activity in humans. Hypertension 1987; 9:42936.

27. Parati G, Di Rienzo M, Mancia G. How to measure baroreflex sensitivity: from the cardiovascular laboratory to daily life. J Hypertens 2000; 18:7-19.

28. Heart rate variability: standards of measurement, physiological interpretation and clinical use. Task Force of the European Society of Cardiology and the North American Society of Pacing and Electrophysiology. Circulation 1996; 93:1043-65.

29. Pinna GD, Maestri R, Torunski A, Danilowicz-Szymanowicz L, Szwoch M, La Rovere MT, et al. Heart rate variability measures: a fresh look at reliability. Clin Sci (Lond) 2007; 113:131-40.

30. Devereux RB, Alonso DR, Lutas EM, Gottlieb GJ, Campo E, Sachs I, et al. Echocardiographic assessment of left ventricular hypertrophy: comparison to necropsy findings. Am J Cardiol 1986; 57:450-8.

31. Netzer NC, Stoohs RA, Netzer CM, Clark K, Strohl KP. Using the Berlin Questionnaire to identify patients at risk for the sleep apnea syndrome. Ann Intern Med 1999; 131:485-91. 
32. Noll G, Wenzel RR, Schneider M, Oesch V, Binggeli C, Shaw S, et al. Increased Activation of Sympathetic Nervous System and Endothelin by Mental Stress in Normotensive Offspring of Hypertensive Parents. Circulation 1996; 93:866-9.

33. Barretto AC, Santos AC, Munhoz R, Rondon MU, Franco FG, Trombetta IC, et al. Increased muscle sympathetic nerve activity predicts mortality in heart failure patients. Int J Cardiol 2009; 135:302-7.

34. Sigurdsson A, Held P, Swedberg K. Short- and long-term neurohormonal activation following acute myocardial infarction. Am Heart J 1993; 126:1068-76.

35. Micieli G, Cavallini A. The autonomic nervous system and ischemic stroke: a reciprocal interdependence. Clin Auton Res 2008; 18:308-17.

36. Heymans C, Neil E. Reflexogenic Areas of the Cardiovascular System. Boston, MA: Little, Brown; 1958.

37. Garrigue S, Bordier P, Jais P, Shah DC, Hocini M, Raherison C, et al. Benefit of atrial pacing in sleep apnea syndrome. N Engl J Med 2002; 346:404-12.

38. Javaheri S. A mechanism of central sleep apnea in patients with heart failure. $\mathrm{N}$ Engl J Med 1999; 341:949-54.

39. van de Borne P, Oren R, Anderson EA, Mark AL, Somers VK. Tonic chemoreflex activation does not contribute to elevated muscle sympathetic nerve activity in heart failure. Circulation 1996; 94:1325-8.

40. Morgan BJ, Crabtree DC, Palta M, Skatrud JB. Combined hypoxia and hypercapnia evokes long-lasting sympathetic activation in humans. J Appl Physiol 1995; 79:205-13.

41. Han JN, Stegen K, Cauberghs M, Van de Woestijne KP. Influence of awareness of the recording of breathing on respiratory pattern in healthy humans. Eur Respir $\mathrm{J}$ 1997; 10:161-6.

42. Parati G, Pomidossi G, Ramirez A, Cesana B, Mancia G. Variability of the haemodynamic responses to laboratory tests employed in assessment of neural cardiovascular regulation in man. Clin Sci (Lond) 1985; 69:533-40.

43. Fasano ML, Sand T, Brubakk AO, Kruszewski P, Bordini C, Sjaastad O.

Reproducibility of the cold pressor test: studies in normal subjects. Clin Auton Res 1996; 6:249-53. 
Table 1: Patient Characteristics (mean \pm SEM)

hypertensive patients

(male/female)

Periodic breathing

$$
\mathrm{n}=7(6 / 1)
$$

$53.3 \pm 4.7$

$28.7 \pm 1.5$

$168.6 \pm 12.9$

$95.8 \pm 4.3$

$61.9 \pm 3.3$ hypertensive patients

Control

$\mathrm{n}=36(24 / 12)$

$59.8 \pm 1.4$

$27.1 \pm 0.6$

$167.8 \pm 3.2$

$94.5 \pm 1.5$

$65.3 \pm 1.8$ 

Table 2: Effects of $\mathrm{O}_{2}, \mathrm{CO}_{2}$ and paced breathing (delta mean $\pm \mathrm{SEM}$ vs. baseline)

\begin{tabular}{|c|c|c|c|c|c|c|c|c|c|}
\hline & & $\begin{array}{c}02 \\
\text { p vs. } \\
\text { baseline }\end{array}$ & $\begin{array}{c}\text { p between } \\
\text { groups }\end{array}$ & & $\begin{array}{c}\text { CO2 } \\
\text { p vs. } \\
\text { baseline }\end{array}$ & $\begin{array}{l}\text { p between } \\
\text { groups }\end{array}$ & & $\begin{array}{c}\text { Paced } \\
\text { Breathing } \\
\text { p vs. } \\
\text { baseline }\end{array}$ & $\begin{array}{l}p \text { between } \\
\text { groups }\end{array}$ \\
\hline $\begin{array}{l}\Delta \text { systolic BP } \mathbf{m m H g} \\
\text { Periodic } \\
\text { Non periodic }\end{array}$ & $\begin{array}{l}1.4 \pm 2.0 \\
-2.1 \pm 1.0\end{array}$ & $\begin{array}{l}\text { ns. } \\
\text { ns. }\end{array}$ & ns. & $\begin{array}{l}4.4 \pm 1.5 \\
6.5 \pm 1.7\end{array}$ & $\begin{array}{c}0.03 \\
0.009\end{array}$ & ns. & $\begin{array}{l}-4.2 \pm 2.7 \\
-3.8 \pm 1.6\end{array}$ & $\begin{array}{l}\text { ns. } \\
0.06\end{array}$ & ns. \\
\hline $\begin{array}{l}\Delta \text { diastolic BP } \mathbf{~ m m H g} \\
\text { Periodic } \\
\text { Non periodic }\end{array}$ & $\begin{array}{l}-0.6 \pm 0.8 \\
-2.4 \pm 0.9\end{array}$ & $\begin{array}{l}\text { ns. } \\
0.03\end{array}$ & ns. & $\begin{array}{l}1.3 \pm 0.6 \\
3.1 \pm 1.2\end{array}$ & 0.04 & ns. & $\begin{array}{l}0.5 \pm 2.4 \\
-3.2 \pm 0.8\end{array}$ & $\begin{array}{c}\text { ns. } \\
0.009\end{array}$ & 0.14 \\
\hline $\begin{array}{l}\Delta \text { HR bpm } \\
\text { Periodic } \\
\text { Non periodic }\end{array}$ & $\begin{array}{l}-1.2 \pm 0.7 \\
-0.9 \pm 1.0\end{array}$ & $\begin{array}{c}0.004 \\
0.03\end{array}$ & ns. & $\begin{array}{l}1.9 \pm 0.7 \\
1.4 \pm 0.7\end{array}$ & $\begin{array}{c}0.05 \\
\text { ns. }\end{array}$ & ns. & $\begin{array}{c}0.1 \pm 0.4 \\
-1.1 \pm 1.3\end{array}$ & $\begin{array}{l}\text { ns. } \\
\text { ns. }\end{array}$ & ns. \\
\hline $\begin{array}{l}\Delta \text { MSA b/min } \\
\text { Periodic } \\
\text { Non periodic }\end{array}$ & $\begin{array}{l}-0.2 \pm 1.3 \\
-0.1 \pm 0.5\end{array}$ & $\begin{array}{l}\text { ns. } \\
\text { ns. }\end{array}$ & ns. & $\begin{array}{l}4.2 \pm 1.3 \\
2.4 \pm 0.7\end{array}$ & $\begin{array}{l}0.03 \\
0.02\end{array}$ & ns. & $\begin{array}{l}-1.8 \pm 0.6 \\
-0.5 \pm 0.8\end{array}$ & $\begin{array}{c}0.04 \\
\text { ns. }\end{array}$ & ns. \\
\hline
\end{tabular}



Fig 1

Normal Breathing

Periodic Breathing
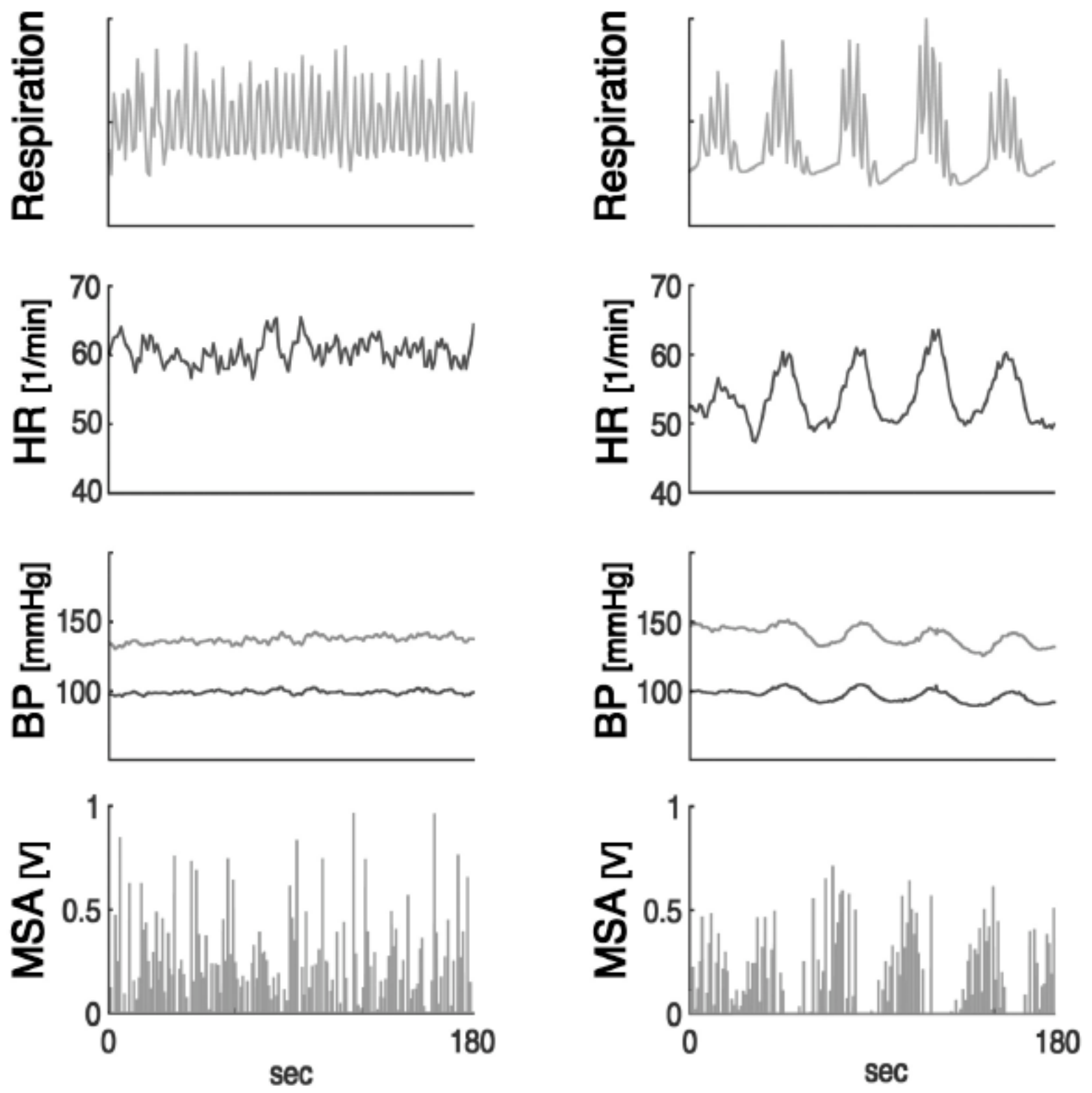
Fig. 2

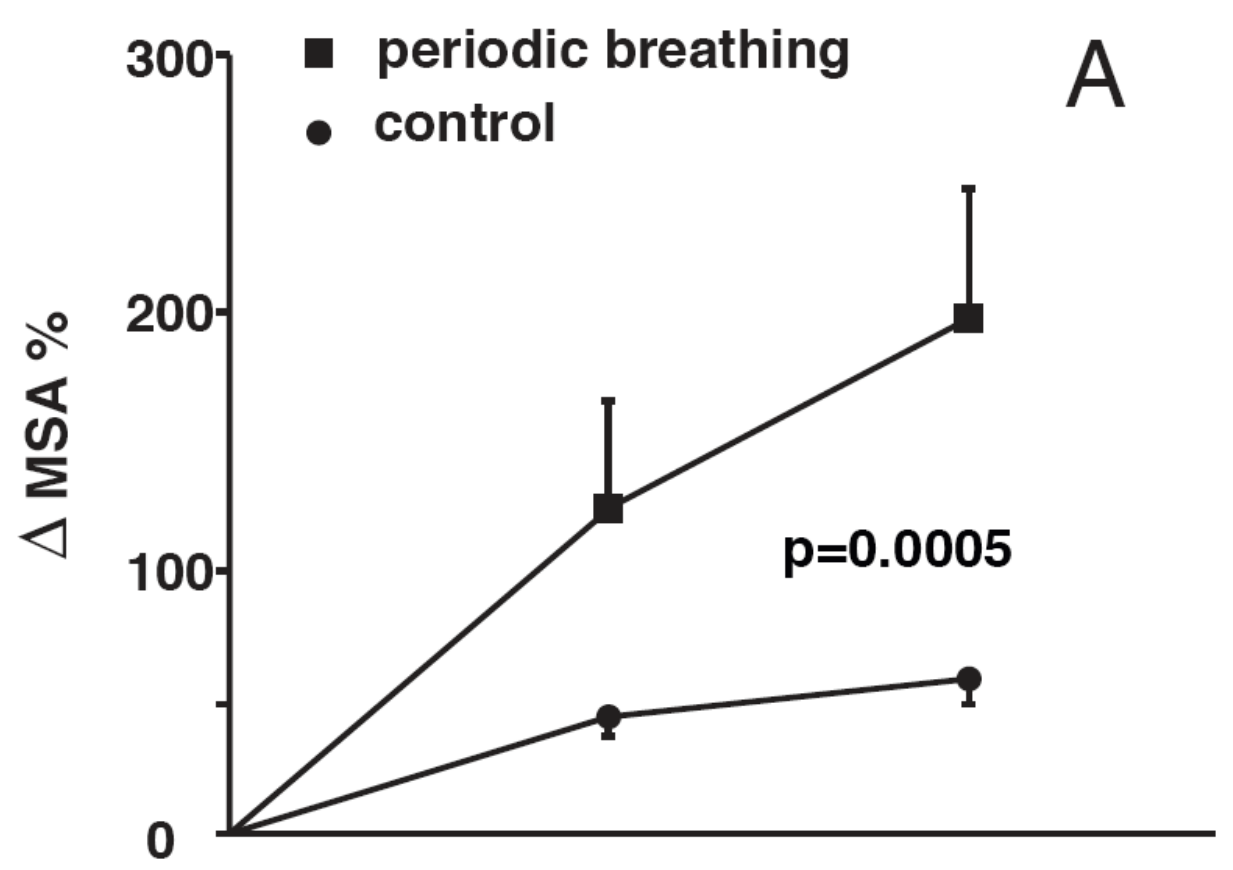


Fig. 3

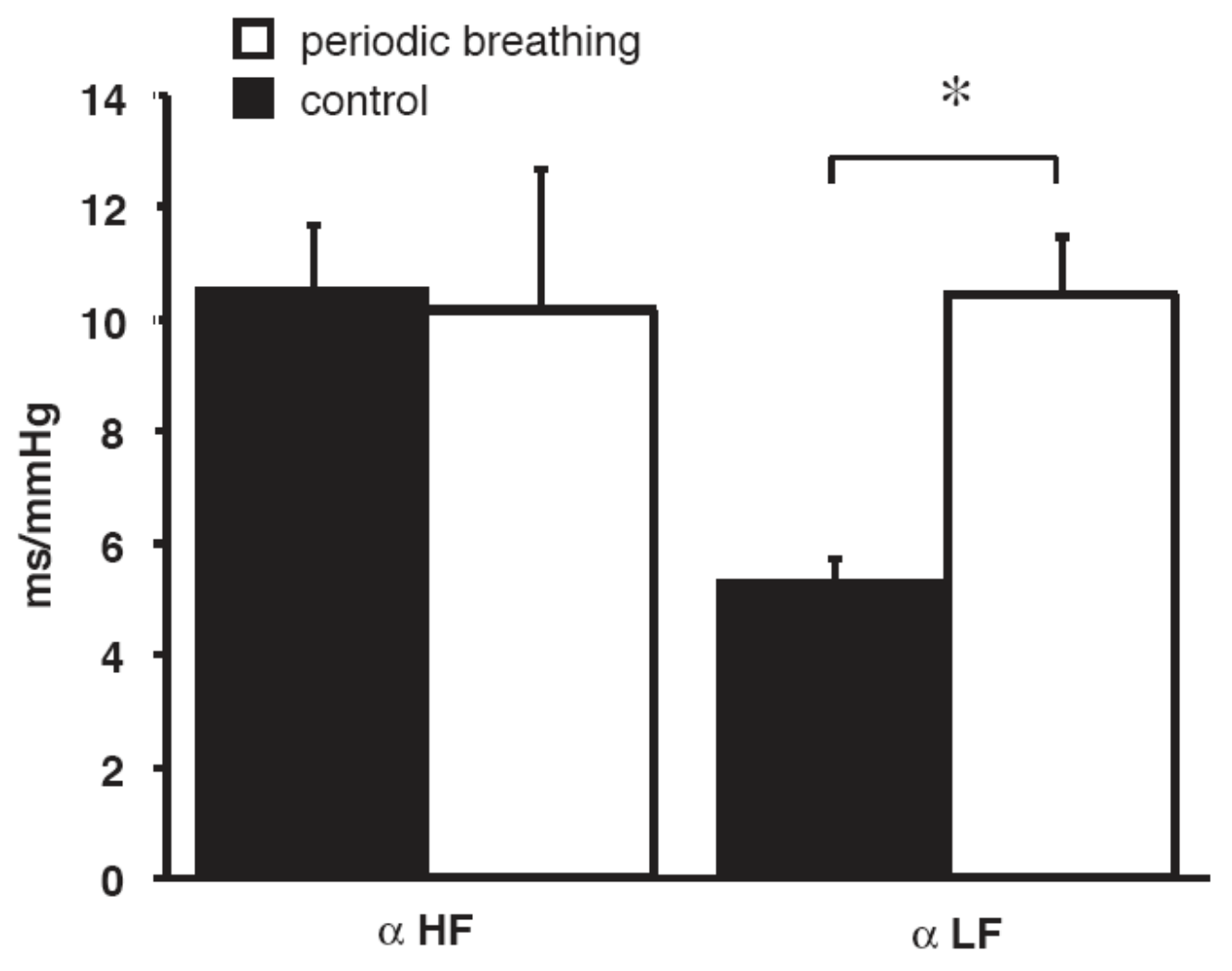

